\title{
The Experience of Being Obese and the Many Consequences of Stigma
}

\author{
Jane Ogden and Cecelia Clementi \\ Department of Psychology, University of Surrey, Guildford Surrey GU2 7XH, UK \\ Correspondence should be addressed to Jane Ogden, j.ogden@surrey.ac.uk \\ Received 15 September 2009; Revised 23 February 2010; Accepted 3 March 2010 \\ Academic Editor: Pietro Forestieri
}

Copyright (๑) 2010 J. Ogden and C. Clementi. This is an open access article distributed under the Creative Commons Attribution License, which permits unrestricted use, distribution, and reproduction in any medium, provided the original work is properly cited.

\begin{abstract}
The present qualitative study aimed to explore how people experience their obesity and to explore the impact of this on their motivations to lose weight. Participants $(n=46)$ were either currently obese or had been obese and were interviewed about their experiences. Participants described the impact of obesity on aspects of their self-identity and used language such as "ugly", "freak", "hate", "blob", and "disgust" which reflected the pervasively negative impact of their weight. They highlighted a complex and often contradictory relationship with food and described how such negative experiences were created out of the dynamic between their obesity and a stigmatising social context. Some, however, suggested that such stigma could also have positive consequences by promoting and encouraging behaviour change. Many obese people, therefore, experience their weight in profoundly negative ways as a result of existing within a social context which stigmatises their condition. The results are discussed in terms of the costs and benefits of stigma and a balance between support, tolerance, and collusion in promoting weight loss.
\end{abstract}

\section{Introduction}

Obesity has been associated with cardiovascular disease, diabetes, joint trauma, back pain, cancer, hypertension and mortality (e.g., [1]). Research has also examined the relationship between psychological problems and obesity. Some research indicates that being obese may not always have a negative impact upon an individual's psychological state [2]. A number of studies, however, suggest that being obese can be detrimental and have tended to focus on depression. Some studies have explored levels of depression in those waiting for surgical treatment for their obesity and consistently show that such patients report more depressive symptoms than average weight individuals (e.g., $[3,4])$. In addition, Rand and McGregor [5] concluded that individuals who had lost weight following gastric bypass surgery stated that they would rather be deaf, dyslexic, diabetic, have heart disease, or acne than return to their former weight. More recently, Simon et al. [6] carried out a large survey on over 9,000 adults in the US and concluded that obesity was associated with increased lifetime diagnosis of a number of depression-related problems.
It is likely, however, that being obese has a more complex impact upon the individual and to explore this research has also assessed the relationship between obesity and other forms of psychological morbidity. For example, Tuthill et al. [7] not only reported high levels of depression but also increased anxiety, poor body image, and impaired quality of life. Similarly, Grilo et al. [8] reported high levels of body image dissatisfaction which were higher in obese women than obese men, Sarwer et al. [9] reported body dissatisfaction particularly with the waist or abdomen, and Wardle et al. [10] reported that greater body dissatisfaction in the obese was higher in those who had developed obesity prior to age 16. Likewise Hill and Williams [11] explored psychological health in a non-clinical sample of obese people and concluded that those with a BMI greater than 40 reported more body dissatisfaction and poorer self-esteem than the lighter obese people.

Research, therefore, indicates that obesity not only influences individuals' health, but also their psychological state. In particular, research highlights a role for depression, anxiety, self-esteem, and body dissatisfaction. This is further supported by research exploring the effectiveness of 
obesity treatment such as behavioural, medical, and surgical interventions which illustrate that weight loss can result in improvements in these areas [12-14]. Such research, however, has explored the psychological impact of obesity using quantitative methods and drawing upon preexisting instruments. It is likely, however, that the experience of being obese is broader and more complex than that accessed by such tools. In addition, such research does not explore the social origins of any psychological consequences. This is particularly pertinent to obesity given its status as a highly stigmatised condition which generates a multitude of social reactions. The literature distinguishes between enacted stigma and felt stigma. In terms of obesity, the negative views of others constitute enacted stigma and have been explored in detail. For example, research suggests that people of all ages, sexes, and from a number of different cultures stigmatise and subsequently discriminate against obese people. In particular, the obese have been rated as more unattractive [15], lacking self-discipline [16], lazy [17], unpopular [18], and less active, intelligent, hardworking, successful, athletic, and popular [19] than their thinner counterparts. Studies also indicate that fat women are judged more negatively than fat men and that these stereotypes are independent of the body size of the person doing the rating [16]. Research also shows that such negative stereotypes may result in discrimination in the college and work place as overweight men and women were less likely to be recommended for employment by college students after being watched performing tasks in an identical fashion to their thinner counterparts [20]. Such negative views have been reported among a range of populations including university admissions personnel [21], business persons [22], rehabilitation counsellors [23], doctors [24] and medical students [25]. For example, in one early study Maddox and Liederman [26] asked a group of physicians, and medical students to rate their overweight patients for a set of personal characteristics. They found that $97 \%$ judged them stupid, $90 \%$ unsuccessful, $90 \%$ weak, $86 \%$ lazy, 69\% not nice, 65\% unhappy, 60\% weak willed, $54 \%$ ugly, and 55\% awkward. The enacted stigma towards obesity is, therefore, well documented. Some research has also explored how enacted stigma may impact upon the obese individual. In particular research has examined the role of teasing both in childhood and as an adult. For example, Matz et al. [27] reported that adult teasing predicted body image dissatisfaction in a group of obese women seeking weight reduction. Similarly, Stormer and Thompson [28] described how social comparison and a history of teasing related to body dissatisfaction and eating disturbance in students and similar results were reported for a sample of obese adults [8]. How such enacted stigma impacts upon an individual's felt stigma remains unexplored. In particular, in light of the numerous attempts at weight loss made by the obese, the present study also aimed to explore the role that stigma plays in helping or hindering motivations for behaviour change.

Obesity is, therefore, a highly stigmatised condition which can be associated with a range of psychological states. How obesity is experienced by the obese person remains unexplored. Furthermore, the ways in which enacted stigma may influence this experience is a neglected area of research, particularly the impact of stigma on motivations for change. In line with this, the present study aimed to explore the experience of being obese using qualitative methods as a means to provide a richer insight than that revealed through the use of preexisting measurement tools. In addition, the study aimed to explore the ways in which the experience of being obese is influenced by having a condition which is subjected to such enacted stigma and to assess the potential impact of such stigma on motivations for change.

\section{Method}

2.1. Design. The study used a qualitative design with indepth interviews.

2.2. Sample. The study aimed to explore the experiences of a heterogenous sample of participants with a range of different experiences of obesity involving different forms of obesity management with differing degrees of success. Participants were either obese $(n=22)$ or had been obese $(n=24)$ and were recruited from a hospital obesity clinic, a General Practice, or the General Public. Those who had lost weight had done so through surgery $(n=12)$, obesity medication $(n=6)$, or behavioural methods $(n=6)$. Those who had not lost weight were trying to do so by being on the waiting list for surgery $(n=7)$, by taking obesity medication $(n=6)$, or by engaging in behavioural management $(n=6)$. All those who had either had surgery or were waiting for surgery had a BMI $>40$. Those who had received medication or were using behavioural methods had a BMI > 30. Just over half of the participants were women $(n=28)$ and they ranged in age from 25 to 62 . Data from those who had had surgery or were taking obesity medication was collected as part of studies designed to assess the experience of the medical and surgical management of obesity. Participants' specific experiences of these forms of management have been published elsewhere [29-31]. Data from those who had lost weight and maintained this weight loss was collected as part of a study designed to assess sustained behaviour change which also focused on smoking cessation. This process of sustained behaviour change has also been published elsewhere [31]. The present study represents a pooled analysis of responses from these studies relating to the experience of being obese. Participants' characteristics are shown in Table 1. All participants have been given a pseudonym.

2.3. Procedure. Interviews took place either face to face or by telephone and were carried out by J. O., C. C., S. S., and L. H., who are all psychologists (undergraduate/postgraduate/Professor). Face-to-face interviews enable the interviewer to encourage the interviewee to speak openly through the use of nonverbal communication such as nodding and smiling. Telephone interviews cannot offer this. Research shows, however, that telephone interviews can also elicit open and honest responses and the interviewee feels safer and more anonymous; as soon as the interview is 
Table 1: Participants' Demographics.

\begin{tabular}{|c|c|c|c|c|}
\hline Name & Sex & Age & Method used & Weight loss \\
\hline Caroline & $\mathrm{F}$ & 35 & Surgery & Yes \\
\hline Angela & $\mathrm{F}$ & 37 & Surgery & Yes \\
\hline Emma & $\mathrm{F}$ & 33 & Surgery & Yes \\
\hline Cathy & $\mathrm{F}$ & 33 & Surgery & Yes \\
\hline Jenny & $\mathrm{F}$ & 25 & Surgery & Yes \\
\hline Mia & $\mathrm{F}$ & 48 & Surgery & Yes \\
\hline Pat & $\mathrm{F}$ & 43 & Surgery & Yes \\
\hline Alison & $\mathrm{F}$ & 46 & Surgery & Yes \\
\hline Fiona & $\mathrm{F}$ & 54 & Surgery & Yes \\
\hline Sonia & $\mathrm{F}$ & 49 & Surgery & Yes \\
\hline Michael & M & 41 & Surgery & Yes \\
\hline Jane & $\mathrm{F}$ & 50 & Surgery & Yes \\
\hline Linda & $\mathrm{F}$ & 51 & Medication & Yes \\
\hline Marion & $\mathrm{F}$ & 40 & Medication & Yes \\
\hline Roger & M & 58 & Medication & Yes \\
\hline David & M & 47 & Medication & Yes \\
\hline Tanvir & M & 44 & Medication & Yes \\
\hline Matthew & M & 43 & Medication & Yes \\
\hline Andrew & M & 25 & Behavioural & Yes \\
\hline Nicky & $\mathrm{F}$ & 33 & Behavioural & Yes \\
\hline Helen & $\mathrm{F}$ & 32 & Behavioural & Yes \\
\hline Jacob & M & 26 & Behavioural & Yes \\
\hline Jackie & $\mathrm{F}$ & 32 & Behavioural & Yes \\
\hline Louise & $\mathrm{F}$ & 47 & Behavioural & Yes \\
\hline Marie & $\mathrm{F}$ & 62 & Medication & No \\
\hline Agnes & $\mathrm{F}$ & 61 & Medication & No \\
\hline Frances & $\mathrm{F}$ & 57 & Medication & Regained \\
\hline Pat & $\mathrm{F}$ & 34 & Medication & Regained \\
\hline Peter & M & 49 & Medication & Yes \\
\hline Kate & $\mathrm{F}$ & 33 & Medication & No \\
\hline Sue & $\mathrm{F}$ & 48 & Waiting list & No \\
\hline Martin & M & 70 & Behavioural & No \\
\hline Chris & M & 46 & Waiting list & No \\
\hline Mark & M & 36 & Behavioural & No \\
\hline Lisa & $\mathrm{F}$ & 47 & Behavioural & No \\
\hline Karen & $\mathrm{F}$ & 53 & Waiting list & No \\
\hline Vicky & $\mathrm{F}$ & 43 & Behavioural & No \\
\hline Lois & $\mathrm{F}$ & 50 & Waiting list & No \\
\hline Anna & $\mathrm{F}$ & 34 & Waiting list & No \\
\hline Denise & $\mathrm{F}$ & 35 & Behavioural & No \\
\hline Lauren & $\mathrm{F}$ & 52 & Waiting list & No \\
\hline Freddie & M & 34 & Waiting list & No \\
\hline Joy & $\mathrm{F}$ & 42 & Behavioural & No \\
\hline Sarah & $\mathrm{F}$ & 20 & Behavioural & No \\
\hline Enid & $\mathrm{F}$ & 29 & Behavioural & No \\
\hline
\end{tabular}

stopped and the phone is put down, they can return to their life without feeling reminded or embarrassed about what they have revealed. In addition telephone interviews are less intrusive as the interviewee does not need to prepare his house for a visitor or worry about what to wear [32].
Interviews lasted between 40 minutes and one hour and 15 minutes. Although face-to-face interviews tend to last longer than telephone interviews, this was not the case for the present study as all participants were highly motivated to describe their experiences of being obese and how they had tried to lose weight. All interviews were audiotaped and transcribed verbatim. Written consent was obtained from those recruited through the hospital and General Practice and verbal consent was obtained from those recruited from the general public. Ethical approval was given by the Hospital Ethics committee, the Local Research Ethics committee, and the University Ethics committee. Approval was also obtained from the Research and Development committees for the clinical participants.

2.4. Interview Schedule. The interview schedule varied according to the sample being interviewed. The questions asked for each sample and the results from other aspects of the data are published elsewhere, which explores the experience of taking obesity medication [30], the experience of obesity surgery $[12,29]$, and sustained behaviour change [31]. Each interview, however, contained the same questions relating to the participants' experiences of being obese. To this end the interviews included questions regarding the experience of being obese such as "How has your weight affected how you feel about yourself?" and "How has your weight affected your life". Those who had lost weight were also asked "How has losing weight affected how you feel about yourself?" and "How has losing weight affected your life in general". The present paper presents the pooled results from these parts of the interview schedules.

2.5. Data Analysis. The interviews were analyzed using thematic analysis to identity major themes, subthemes and categories in line with the recommendations of Huberman and Miles [32]. The transcripts were read and reread to ensure familiarity with the data. For each interview a coding sheet was constructed. This sheet contained all possible themes and subthemes for the interview. References to original material were recorded under each theme. From the individual summary sheets an overall list of themes was constructed. With continuous reference to the transcripts, shared themes and connections across the list of themes were made. All the verbatim transcripts were re-read to ensure that the themes were representative of the original material. Throughout the write-up process, themes and sub-themes were adjusted and illustrative quotes were identified.

\section{Results}

The participants described their experience of being obese in a range of ways. The main themes to emerge from this analysis were the impact of obesity, the meaning of food, and the role of the social context. Transcending these themes was the implications of this experience for an individual's motivations for change. These will now be described with the use of illustrative quotes. 
3.1. The Impact of Obesity. Participants described the multitude of ways being obese impacted upon their self-identity and their lives in general. In particular they described how it had influenced their mood, their self-perception, a feeling of dissociation, and their health and how these factors had been reversed following weight loss.

Participants described the emotional consequences of their weight using terms such as "miserable", "depressed", "disgust", "killing myself", "ashamed", "guilt", and "hate". For example, one woman who was trying to lose weight said,

"when you are low you just feel oh no everyone thinks I'm this great big blob and it's horrible, it's hell and hard to get on with life and you just feel big. .. it's so much hard work being this size..." (Karen).

Similarly, Enid described how she felt anger:

"Its not guilt, I'm too realistic to feel guilty. I don't think you should feel guilty about something you've chosen to do. It's more anger at myself. . . Anger, it's a sort of self hate...it's anger at my inability to stop eating" (Enid).

The majority of participants also described how being obese had a detrimental impact upon how they perceived themselves and their self identity. They used terms such as "freak", "ugly", "horrible", "insecure", "unconfident" and "low self-esteem". For example, one woman who was on the waiting list for surgery said,

"I feel like I'm ugly, I'm a freak. When I take my clothes off it's not nice. I won't let anyone see me like that. .. I do not like people seeing me and my boobs, my stomach, I've got fat on my back" (Sue).

Sarah also described how she felt about her body in very graphic ways:

"I think my face is alright. It's just my body. I don't like looking at my body. Not at all. When I look at it I feel sick... My legs rub together, my belly hangs and every minute I'm trying to pull my trousers down and put my top down when I'm walking. Horrible." (Sarah).

In contrast, however, a few felt that their obesity had had no effect on their self perception. For example, Freddie said,

"I've always felt that I look good and I'm fine because that's how I see myself. ... I'm quite confident and all that so I do not allow things to upset me" (Freddie).

Lisa even felt that she had become a better person because of her weight:

"I'm a bit more rounded...Since I've become unwell and since I became like this there's areas of grey and that's actually been of great benefit to me. . doesn't being fatter and unwell I think has actually made me a nicer person. It brought out the gentle side of me that I like better" (Lisa).

Many participants also described how their weight made them feel dissociated from their body and used terms such as "trapped", "not me", and "does not belong to me" and stated that they felt someone had "switched my body". This dissociation was particularly apparent in the interview with one woman who although she had lost 6 stone was still overweight:

"My body doesn't belong to me at all. Because I'm not a naturally fat person, being big. .. everything is alien. I've got no links with the Lisa in the format that I am now, not at all" (Lisa).
It also clearly emerged in the narrative of one woman who had gained most of her weight during pregnancy and was waiting for surgery:

"When I had my baby they must have switched my body with somebody. ... I say its not my body. .. there's a raunchy skinny Cindy Crawford trying to get out, she's got to find the right orifice" (Anna).

The final way in which the participants felt that their weight had impacted upon their life was in terms of their health. In particular they described a range of health problems including heart problems, gangrene, diabetes, joint pain and breathlessness. One woman who was waiting to have surgery described,

"I can't even lay flat on my bed. I have to have pillows under me because as soon as I lay down, because I am quite big chested, I feel like I'm suffocating, so I find it really difficult so I sit up, I sit up almost up straight" (Anna).

Similarly another woman described how her weight made her feel very unfit and that losing weight would give her back her freedom:

"Freedom just to do things, freedom to walk up stairs and back down again. Freedom to do my housework without puffing and painting, just freedom to go shopping. .. I feel like I've had part of my life just taken away from me, robbed from me.... All that I want it's just really mobility...”. (Vicky).

Being obese, therefore, seemed to affect most areas of people's lives and in general the impact of obesity was quite negative. Those within the sample who had lost weight described how weight loss reversed these negative effects and resulted in improvements across a range of domains. These can be seen to reflect all the domains highlighted as being influenced in the first place as people reported improvements in their self perception and their mood; they felt less dissociated from their bodies and their health had improved.

For example, those who had lost weight described how they felt as "confident", "happy", and "proud". For example, one man who had lost weight through surgery described how he now felt:

"I feel more confident... I'm less embarrassed and not self conscious anymore and my body language has changed. I can just lean back in my chair and talk... I feel like I've got a new life, new chances, new opportunities. I'm a new person... It is a rebirth really" (Michael).

Similarly they described how they were now "normal" and could be more active and reengage with their lives in terms of looking after the children, finding work, and generally being more active and "taking more care" and "making more effort" with themselves. One woman said:

"I realised there was a life and I would be able to work because I was petrified of losing my career, my life, everything. ... Now I'm well... I've got self esteem, I've got confidence and the more weight I lose the better I feel" (Jane).

For those who had lost weight there, therefore, seemed to be a return to normal functioning and an improvement in all the areas of their lives which had been undermined by their weight. This shift in perspective did not, however, happen immediately and many described a delay in the process and 
a period of readjustment. One woman said who had lost weight:

"I can't focus on what I really look like because I still see myself in a size thirty dress... I went shopping with my daughter and I went to the same old shop, like the big shop, and she went to me, Mum you don't need to go in there" (Alison).

Participants therefore described a range of ways being obese effected their lives. For the majority these consequences were negative and involved a negative sense of self, negative affect, a sense of dissociation and concerns about their health. The strength of the impact of obesity was further illustrated by the language used which was often highly emotive such as "freak", "hate" and "ugly" or dismissive such as "blob". A small minority however, felt that their weight had had no or little impact and a couple also described how the consequences were positive. Actual weight loss seemed however, to be able to reverse many of these effects. Previous research has emphasized the impact of obesity on body image and body dissatisfaction (e.g., $[7,10])$. The present study supports this association but provides further evidence for how this dissatisfaction is experienced by the individual. Previous studies have also explored levels of depression and anxiety in the obese and suggest that obesity is associated with increased negative affect (e.g., $[4,6])$. The present study supports these findings but suggest that the use of quantitative measure may miss aspects of the obesity experience with the interviews using highly descriptive language which illustrates the strength and power of their feelings. Furthermore, the present study indicates that such negative emotion may result in the individual distancing themselves from their physical body. Finally whilst many studies illustrate the health consequences of obesity the results from this study indicate that health concerns and health worries are central to the experience of being obese. Such negative consequences are not permanent however, as the interviewees also described how each of these aspects improved if they had lost weight, although this improvement was not always immediate and involved a process of adjustment. The results from the present study therefore illustrate that the impact of obesity is much more wide ranging and profound than often described and that it influences a multitude of aspects of an individual's experience of self.

3.2. The Meaning of Food. All interviewees, whether they had lost weight or not, described a range of roles that food played in their lives and highlighted a complex set of meanings associated with eating and not eating. Although a few emphasised the importance of the biological drives hunger and satiety the majority felt that their eating was related to other factors such as emotional regulation, issues of control and their social world. As one woman said of hunger:

"the hunger is not actually a hunger pain, it's the activity of the eating as well. It's filling the mouth or it's doing something and if you can try and do something else then you can. That's what it is, you mustn't think about it and it's easier..." (Lisa).
Similarly, Sarah argued,

"It's not hunger. I'm never, ever hungry. I'm just greedy but I've learnt that sometimes I can't control myself" (Sarah).

Many participants described how food played in central role in the way they managed and regulated their emotions. They talked about eating when they were depressed, for comfort and support, as a means of coping and how food could make them feel guilty.

Some described how only specific foods had an emotional effect:

"Now I could eat a bit of chocolate if I'm upset or I'm tired or feeling vulnerable, I will go for the chocolate or crisps so I can comfort eat. ... I think it's important to eat something but if it's chocolate or sweets it's better to comfort eating..." (Denise).

Using food for mood repair, however, was not always successful. For example, one woman described her complex reactions to food:

"I use it so much as a way of trying to control my emotions although of course it never does and makes it worse. It's not a friend, but it's an emotional support. .. I have a sort of love hate relationship with food" (Enid).

In line with this, another described how food made her feel worse about herself:

"I constantly feel guilty when I'm eating something. Like I'll eat a big bar of chocolate and then I'll feel guilty, I'll eat a pack of crisps and then I wish I hadn't eaten that, I wish I had something left but that's an ongoing thing." (Sue).

A few, however, described how eating and their emotions were unrelated. These were in the minority but involved a focus on taste, hunger, and fullness:

"I just really like food. I enjoy eating and I don't think I'm never binge or comfort eating" (Freddie).

For many, food was related to issues of control and many likened their relationship to food to an addiction, an obsession, or being an alcoholic. For example, Anna described how thinking about food had started to take over much of her life:

"I think about it all the time and it becomes an obsession and I've start waking up in the night to eat... and the obsession is that I know that I shouldn't be thinking it..." (Anna).

She also described how her eating was beyond her control and used language which suggested that the hand doing the eating was separate from her mind:

"I know what the problem is but I can't physically stop it. I need help to stop it because once my hand's doing that, until I've got that full feeling there's no point in me stopping because I will keep going" (Anna).

Similarly one woman who had started to lose a lot of weight also described her lack of control over food:

"...I think it's like being an alcoholic and I think that's how it will have to be for me...so it's the price I've had to pay to lose the weight is to lose the interest in food" (Lisa).

Some offered analyses as to where their problems with control had come from and many focused on their childhood. For some, their relationship to food had emerged from poor relationships within their family. For many, the lack of control came from having been denied food as a child: 
"my mum didn't control me because she didn't want me so all my life is having someone to control. If they control me, I would lose weight. ... It's like being a kid and being told that you can't eat that. When you've got to be an adult you can do exactly what you want to do so you're gonna do .... Because they've told you not to, you'll eat it. I mean if they told you to eat it you wouldn't it. It's like trying to get discipline in your life and you can't". (Sue).

The majority of interviewees described how eating plays a central part in their social lives and emphasised how they ate as part of family life and used food to mark a celebration and how they provided food for others as a sign of love and caring.

For example, one man described how mealtimes had played a central place in his childhood and how this had influenced his relationship to food as an adult:

"Being Latin, we talk about food, we sit around the table the whole family. ... It's also the way I was programmed from when I was kid. You have to finish everything on your plate so I would overcook, I would put everything on the plate and I would eat it. You don't throw away food" (Mark).

Participants, therefore, described a range of roles that food and eating played in their lives. Although some described the biological basis to eating in terms of hunger and fullness, for the majority eating was more complex than this. In particular, many used food for emotional regulation and ate for comfort, support, and as a coping mechanism although some described how this was only temporarily effective leaving them feeling guilty. Some also described how food was linked with issues of control and described food as an addiction derived from aspects of their childhood and relationship with others. Further, food was seen as central to most participants' social world. Previous research highlights the many ways in which food can be used as a forum for communication and how it serves many functions beyond that of satisfying hunger (e.g., [33-35]). The results from the present study illustrate how many obese people are aware of their uses of food and the role that it plays in their lives. The results also highlight how these roles may not always be effective and beneficial to the individual and that even though the obese may recognize how and why they eat they are often unable to change their behaviour.

3.3. The Social Context. The third theme to emerge was the impact of the social context and all participants described how their reaction to being obese was exacerbated and created by their social context and how weight loss made fitting into their social world easier. One woman said, "it's a sort of vicious circle about how I see myself and how people see me" (Lisa). This social context influenced the interviewees in terms of the practicalities of day-today life, wanting to be normal, the role of others, and being discriminated against. In contrast, some described the potential benefits of their social context.

Many interviewees described the problems they faced by being obese in a world designed for thinner people. They provided a multitude of examples of day-to-day behaviours which were problematic due to their weight including shopping for clothes, putting on their shoes and socks, playing with children, becoming stuck in the bath, not being able to fit into bus seats or chairs, and having problems doing housework.

For example, one man who was trying to lose weight through behavioural methods, described:

"I'm not too happy. It is starting to affect me.... I find it difficult to put my socks on and if I'm standing I need to sit down to do it and I don't like that. I'm only 36" (Mark).

Similarly one woman said,

"Even if I'm getting a bus to work, if there's two people and one is sat in one, I won't sit in the next one because I'm too big and I might squash them. I probably wouldn't but that's just the way you feel so I just stand up...” (Lauren).

Further one woman who had had surgery described how her life had been affected:

"I couldn't walk very far, I couldn't bend down, I couldn't tie my shoe laces, I couldn't walk upstairs... if my shoelaces came undone I would have to wait until I could find something to put my leg on to reach... You can't live like that" (Sonia).

In line with these difficulties, many participants described how they felt "different" and "abnormal", how they wanted to be "just normal", and how they felt that there was a "taboo" associated with their size. For example, one woman described,

"I don't wanna be Jo Lo because its impossible, I'm big bones anyway, but I wanna reach the stage where I can be flexible like a slim person and where I can buy normal clothes...size 12 or 14 would be normal for me" (Sarah).

Some also described how they managed feeling abnormal by wearing a mask. For example, one woman said,

"I'm quite talkative and an outgoing person. I'm not so shy but I use my personality I think more than a slimmer person would have. Maybe that's why I am usually always cheery... It's a bit of a mask you put on ... .You have to be some kind of joker... you feel you've got to try so much harder in life to be accepted...you put on a brave face and smile and joke a lot but inside its awful" (Joy).

These influences came from a wide range of other people and interviewees described the role of friends, family, employers, and children in making their obesity an issue for them. For example, one woman described how her children's friends influenced her own self perception:

"My kid came out of school and she was so upset because they'd really been on at her all day and she said "why can't you just be skinny like everybody else's mum?” (Anna).

One described her experiences of doctors:

"Doctors treat you as if ... they don't treat you like a person. You are just fat and that's why you are ill and "go away and lose weight"... People just have you down as being a greedy person" (Lynne).

And one described her experience of relationships:

"what a lot of guys do, they will get themselves a fat woman and cheat on her and treat her like rubbish just because they know she's not going to get no one because she's too big" (Sarah). 
The comments and expectations of others, therefore, influenced their perceptions of themselves and their selfidentity. Many also described how they felt discriminated against. They described how people saw them as "fat and stupid", how they were seen as having "no mind", how jobs were difficult to get, how they did not get promoted, and how they were seen as "lazy" and as having "no drive". One man described how he felt that his weight had influenced his career:

"I get very frustrated because you do telephone interviews and you come across very well and then when they see you they are full of discrimination.... You face more discrimination by being overweight" (Mark).

Similarly Freddie described how

"People that are big don't get promoted as much as they have the perception that maybe they are lazy or they haven't got much drive" (Freddie).

And Sue described how she had been rejected in the past:

"He didn't want to be seen with me... nobody wants to take me anywhere and it hurts...I don't want a relationship now because I don't want to be hurt...its discrimination I reckon. People don't like fat people and they think you're stupid" (Sue).

Not all experiences were negative, however, and a minority described how people had been supportive and caring towards them. For example, Lisa said,

"My husband has loved me when I've been at my fattest so I'm sure that he will love me when I'm at my thinnest" (Lisa).

Participants, therefore, described how their social context influenced their perceptions of themselves and influenced the way they experienced being obese. For the majority, the reactions of others and even their expected reactions of others left them feeling abnormal, that they were being harshly judged, and that the opportunities open to thinner people were not open to them. A minority, however, described how people had been caring and supportive. Previous research has described a series of ways in which obesity generates enacted stigma and negative stereotypes which can result in behaviours such as teasing $[16,27]$. The results from the present study illustrate that such reactions result in felt stigma by the obese person and highlight its impact upon an individual's sense of self and their self identity. Being obese may not be an inherently negative state but a social context which judges it negatively generates, a series of experiences and moods which result in a negative cognitive set.

3.4. Implications for Motivations for Change. Interviewees, therefore, described their experience of being obese in terms of its impact on their lives, the meaning of food and the social context. Transcending these themes was the implications of their experience for their motivation to change and in particular their desire and ability to change their behaviour.

For some who felt that they had experienced minimal stigma as a result of their obesity, behaviour change did not seem to be an option and they seemed content with the status quo. For example, Mark said that,

"who likes me likes me, who doesn't like me doesn't matter if I'm big or small, so I've come to terms with who
I am and I know I will be overweight all my life so obviously I don't like what I see in the mirror but I don't care about it" (Mark).

Similarly, one woman who was attending the hospital clinic and trying to lose weight through behavioural means described how she felt that her life had been too easy:

"I've never been insulted or anything like that. . I've been so comfortable. I've been accepted in society as normal. I haven't been bullied. I've been made so comfortable so I think that's why I haven't done anything about it up to now" (Sarah).

For others, however, social responses and stigma had influenced their motivations for change. For some, this stigma was perceived to have exacerbated their negative sense of self making them more likely to overeat. For example, one woman described how the ways in which people responded to her made her feel miserable which in turn caused her to eat more:

"Food is...when you're depressed, it's your companion isn't it? You wanna have a good time you're gonna eat and you'll eat anything you know...I mean I don't go out, I don't drink, I don't smoke..." (Sue).

Similarly others described how their eating was often triggered by low self-esteem, self-criticism and poor self identity.

Others, however, described some of the benefits of stigma. For example, although Joy described feeling uncomfortable eating in public as she felt people were scrutinising her and, therefore, avoided social situations, she also explained how this caused her to eat less:

"I won't eat in front of people unless we go to a wedding or a do when there's food on the table and I'll just have a small amounts because you're so embarrassed" (Joy).

More specifically, however, some described how the problems encountered through being obese had motivated them to lose weight. For example, one woman who had decided to have surgery for her weight described how this decision had been triggered by an embarrassing event:

"I've even been stuck in the bath and I've had to call my eldest son" (Anna).

And one woman described how her weight loss was motivated by the problems of day-to-day living:

“I couldn't buy clothes, I couldn't wear tights, I couldn't find my feet, I was wearing big shoes" (Ellen).

Transcending these different themes was the implications of the experience of motivations for change. For some the stigma associated with obesity exacerbated their eating problems and encouraged overeating and eating as a form of emotional regulation. Some, however, felt that there were benefits to the social attitudes to obesity and the problems encountered when being obese as they acted as motivations for change.

\section{Discussion}

The present study aimed to explore the experience of being obese. Primarily the interviewees described the impact of being obese on aspects of their sense of self using powerful language such as "freak", "ugly", and "blob" and described 
how they felt uncomfortable about the way they looked. In addition, they highlighted a range of effects on their mood, described a sense of dissociation, and emphasised worries about their health. The results also illustrate the association between being obese and the meaning of food. In particular, the participants highlighted how eating was rarely triggered by hunger but used for emotional regulation, was a social behaviour, and was connected with issues of control with many referring to their eating behaviour as an addiction. Therefore, being obese influences an individual's sense of self and is embedded within a complex and sometimes contradictory relationship with food. Such experiences, however, are not just a consequence of being obese but reflect the dynamic between the obese individual, and their social context. As such, the problems encountered by living in a world designed for thinner people, the judgments of others, a process of discrimination, and a sense of being not normal offer a social context which renders being obese problematic. This is exacerbated by the use of food for emotional regulation which not only fails resulting in further self-criticism but also exacerbates the individual's weight problem. Not all participants, however, painted such a consistently distressing picture. Some described how they existed within relationships whereby they felt appreciated whatever their size and some felt that they had been made a better person because of their size. Further, some believed that stigma, whilst uncomfortable to experience, could have some beneficial consequences. In particular, they described how the practical difficulties encountered on a daily basis and how the judgments and stereotypes could contribute towards their motivation to bring about a change in their behaviour, thereby promoting weight loss. For example, a sense of losing independence by not being able to put one's socks on, a sense that one's career was suffering, or a fear of not being able to find a satisfactory relationship, for some, acted as a trigger for change. The social context may generate a negative sense of self. For some this translates into lowered mood and self-criticism. For some, however, this may offer the opportunity for change and subsequent weight loss which is described as being able to reverse many of the unpleasant consequences of being obese in a stigmatising social world. Recent research suggests that sustained behaviour change may be triggered by life crises or catastrophes $[31,36]$. At times a stigmatising social world may offer up a sense of crisis which may be sufficient to promote change.

In summary, the present study highlights the ways in which being obese in a social context which stigmatizes obesity can result in a negative sense of self which is embedded within a complex and contradictory relationship with food. Further, the results indicate that such experiences can impact upon an individual's motivations to lose weight. These results have implications for both the development of interventions to encourage weight loss and how society responds to obesity.

In terms of the development of successful interventions, the results indicate that health professionals need to understand each individual's own experiences of being obese within their social context and the meanings they assign to food. Furthermore, they need to explore whether negative personal and social responses to their weight are either a hindrance or a help to weight loss. If a hindrance then therapy should focus on self-esteem building and the promotion of a more positive self identity. But if a help, then therapy should encourage the individuals to use their self-criticism as a means to motivate themselves out of their weight problem.

In terms of social responses to obesity, if the obese person is to have a more positive life experience, then either they have to lose weight or society has to become a more tolerant and supportive environment in which one may be obese. Given that losing weight and maintaining any weight loss is very difficult with those that achieve this being in the minority (e.g., [37]), then maybe society should aim to be less judgmental and more supportive of those with weight problems. Such a conclusion is in line with obesity groups who lobby for larger seats in public places and ask for a reduction in discrimination and prejudice. Some participants in this study, however, reported how such a negative social context could have some beneficial consequences, particularly by promoting behaviour change. Stigma, therefore, seems to have potential costs and benefits to the obese person. Perhaps society needs to find the appropriate balance between support which improves the experience of the obese and collusion which facilitates the development and maintenance of obesity through making the life of the obese easier and less of a trigger for change. Such a balance between support and collusion may also help to create an environment in which losing weight and reversing the negative consequences of being overweight can become less of a minority behaviour.

To conclude, being obese is a predominantly negative experience in the broadest sense exacerbated by a world that stigmatises this condition. Such stigma may create a negative sense of self, thus undermining any motivation for change. But for some, in the right conditions, and with appropriate support, stigma may present the sufficient triggers to encourage the changes which are necessary for weight loss.

\section{Acknowledgment}

The authors are grateful to Sunita Sidhu and Louise Hills for carrying out some of the interviews.

\section{References}

[1] W. D. Ashton, K. Nanchahal, and D. A. Wood, "Body mass index and metabolic risk factors for coronary heart disease in women," European Heart Journal, vol. 22, no. 1, pp. 46-55, 2001.

[2] A. F. Jorm, A. E. Korten, H. Christensen, P. A. Jacomb, B. Rodgers, and R. A. Parslow, "Association of obesity with anxiety, depression and emotional well-being: a community survey," Australian and New Zealand Journal of Public Health, vol. 27, no. 4, pp. 434-440, 2003.

[3] R. H. Bull, W. D. Engels, F. Engelsmann, and L. Bloom, "Behavioural changes following gastric surgery for morbid 
obesity: a prospective, controlled study," Journal of Psychosomatic Research, vol. 27, no. 6, pp. 457-467, 1983.

[4] T. A. Wadden, M. L. Butryn, D. B. Sarwer, et al., "Comparison of psychosocial status in treatment-seeking women with class III vs. class I-II obesity," Obesity, vol. 14, supplement 2, pp. 90S-98S, 2006.

[5] C. S. W. Rand and A. M. C. MacGregor, "Successful weight loss following obesity surgery and the perceived liability of morbid obesity," International Journal of Obesity, vol. 15, no. 9, pp. 577-579, 1991.

[6] G. E. Simon, M. Von Korff, K. Saunders, et al., "Association between obesity and psychiatric disorders in the US adult population," Archives of General Psychiatry, vol. 63, no. 7, pp. 824-830, 2006.

[7] A. Tuthill, H. Slawik, S. O’Rahilly, and N. Finer, "Psychiatric co-morbidities in patients attending specialist obesity services in the UK," QJM, vol. 99, no. 5, pp. 317-325, 2006.

[8] C. M. Grilo, D. E. Wilfley, K. D. Brownell, and J. Rodin, "Teasing, body image, and self-esteem in a clinical sample of obese women," Addictive Behaviors, vol. 19, no. 4, pp. 443-450, 1994.

[9] D. B. Sarwer, T. A. Wadden, and G. D. Foster, "Assessment of body image dissatisfaction in obese women: specificity, severity, and clinical significance," Journal of Consulting and Clinical Psychology, vol. 66, no. 4, pp. 651-654, 1998.

[10] J. Wardle, J. Waller, and E. Fox, "Age of onset and body dissatisfaction in obesity," Addictive Behaviors, vol. 27, no. 4, pp. 561-573, 2002.

[11] A. J. Hill and J. Williams, "Psychological health in a nonclinical sample of obese women," International Journal of Obesity, vol. 22, no. 6, pp. 578-583, 1998.

[12] J. Ogden, C. Clementi, S. Aylwin, and A. Patel, "Exploring the impact of obesity surgery on patients' health status: a quantitative and qualitative study," Obesity Surgery, vol. 15, no. 2, pp. 266-272, 2005.

[13] J. Boan, R. L. Kolotkin, E. C. Westman, R. L. McMahon, and J. P. Grant, "Binge eating, quality of life and physical activity improve after Roux-en-Y gastric bypass for morbid obesity," Obesity Surgery, vol. 14, no. 3, pp. 341-348, 2004.

[14] L. E. Bocchieri, M. Meana, and B. L. Fisher, "A review of psychosocial outcomes of surgery for morbid obesity," Journal of Psychosomatic Research, vol. 52, no. 3, pp. 155-165, 2002.

[15] W. DeJong, "The stigma of obesity: the consequences of naive assumptions concerning the causes of physical deviance," Journal of Health and Social Behavior, vol. 21, no. 1, pp. 7587, 1980.

[16] M. Tiggemann and E. D. Rothblum, "Gender differences in social consequences of perceived overweight in the United States and Australia," Sex Roles, vol. 18, no. 1-2, pp. 75-86, 1988.

[17] E. Weiss, "Perceived self-infliction and evaluation of obese and handicapped persons," Perceptual and Motor Skills, vol. 50, no. 3, p. 1268, 1980.

[18] J. R. Staffieri, "A study of social stereotype of body image in children," Journal of Personality and Social Psychology, vol. 7, no. 1, pp. 101-104, 1967.

[19] M. B. Harris, R. J. Harris, and S. Bochner, "Fat, four eyed and female: stereotypes of obesity, glasses and gender," Journal of Applied Psychology, vol. 100, pp. 78-83, 1982.

[20] J. C. Larkin and H. A. Pines, "No fat persons need to apply: experimental studies on the overweight stereotype and hiring preference," Sociology of Work and Occupations, vol. 6, pp. 312327, 1979.
[21] H. Canning and K. L. Mayer, "Women but not men are what they eat: the effect of meal size and gender on perceived femininity and masculinity," Personality and Social Psychology Bulletin, vol. 13, pp. 166-176, 1990.

[22] R. C. Klesges, M. L. Klem, C. L. Hanson, et al., "The effects of applicant's health status and qualifications on simulated hiring decisions," International Journal of Obesity, vol. 14, no. 6, pp. 527-535, 1990.

[23] S. P. Kaplan, "Rehabilitation counselling students' perceptions of obese male and female clients," Dissertation Abstract International, vol. 42, p. 214, 1984.

[24] M. Blaxter, "Diagnosis as category and process: the case of alcoholism," Social Science and Medicine, vol. 12, no. 1, pp. 917, 1978.

[25] H. J. C. Wiese, J. F. Wilson, R. A. Jones, and M. Neises, "Obesity stigma reduction in medical students," International Journal of Obesity, vol. 16, no. 11, pp. 859-868, 1992.

[26] G. L. Maddox and V. Liederman, "Overweight as a social disability with medical implications," Journal of Medical Education, vol. 44, no. 3, pp. 214-220, 1969.

[27] P. E. Matz, G. D. Foster, M. S. Faith, and T. A. Wadden, "Correlates of body image dissatisfaction among overweight women seeking weight loss," Journal of Consulting and Clinical Psychology, vol. 70, no. 4, pp. 1040-1044, 2002.

[28] S. M. Stormer and J. K. Thompson, "Explanations of body image disturbance: a test of maturational status, negative verbal commentary, social comparison, and sociocultural hypotheses," International Journal of Eating Disorders, vol. 19, no. 2, pp. 193-202, 1996.

[29] J. Ogden, C. Clementi, and S. Aylwin, "The impact of obesity surgery and the paradox of control: a qualitative study," Psychology and Health, vol. 21, no. 2, pp. 273-293, 2006.

[30] J. Ogden and S. Sidhu, "Adherence, behaviour change and visualisation: a qualitative study of patient's experiences of obesity medication," The Journal of Psychosomatic Research, vol. 61, pp. 545-552, 2006.

[31] J. Ogden and L. Hills, "Understanding sustained changes in behaviour: the role of life events and the process of reinvention," Health, vol. 12, pp. 419-437, 2008.

[32] A. M. Huberman and M. B. Miles, Data Management and Analysis Methods, Sage, London, UK, 1994.

[33] M. Douglas, Implicit Meanings, Routledge, London, UK, 1975.

[34] R. A. Gordon, Eating Disorders: Anatomy of a Social Epidemic, Blackwell, Oxford, UK, 2nd edition, 2000.

[35] J. Ogden, The Psychology of Eating: From Healthy to Disordered Behaviour, Blackwell, Oxford, UK, 2003.

[36] R. West, Theory of Addiction, Blackwell, Oxford, UK, 2006.

[37] NHS Centre for Reviews and Dissemination, Systematic Review of Interventions in the Treatment and Prevention of Obesity, University of York, New York, NY, USA, 1997. 


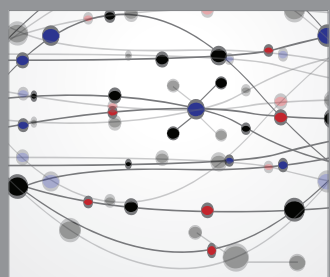

The Scientific World Journal
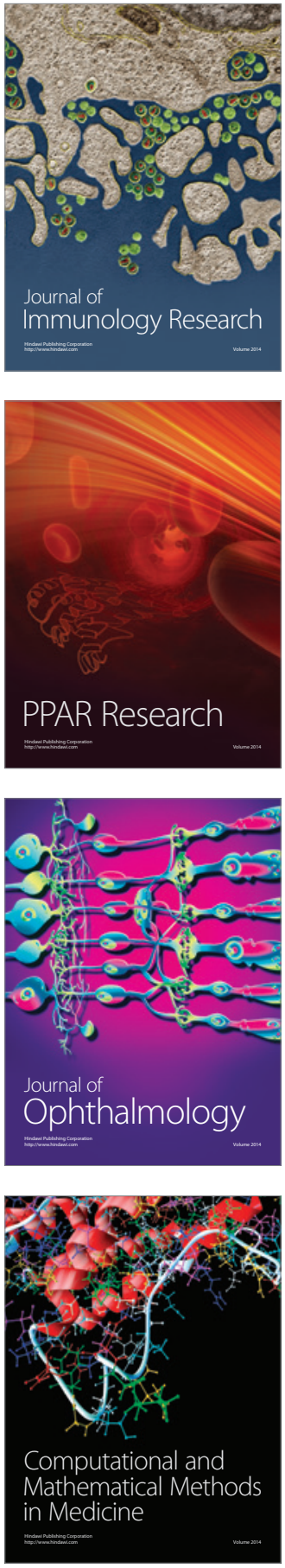

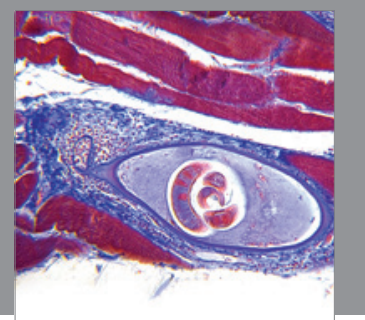

Gastroenterology

Research and Practice
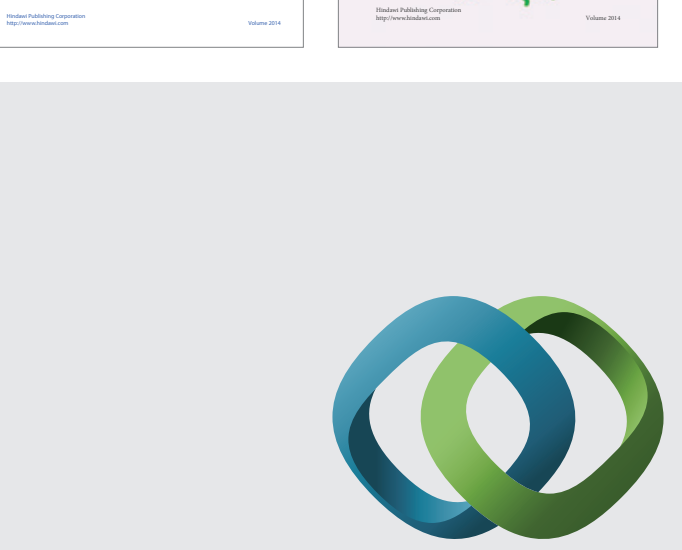

\section{Hindawi}

Submit your manuscripts at

http://www.hindawi.com
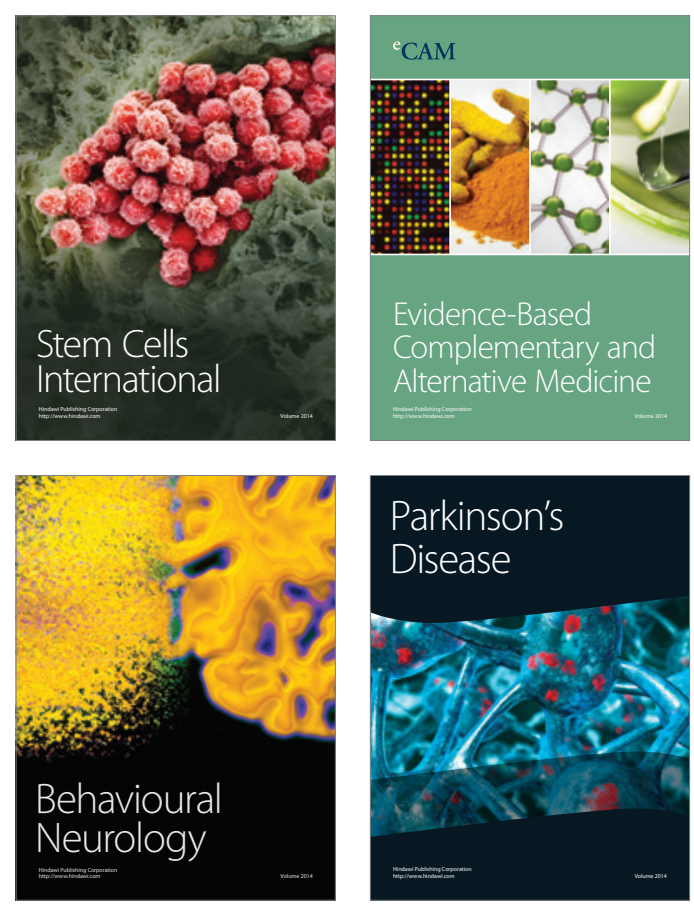

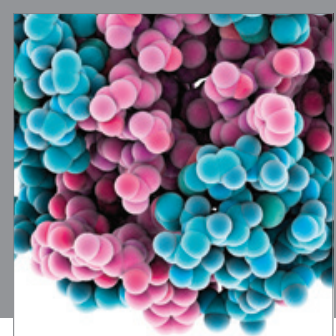

Journal of
Diabetes Research

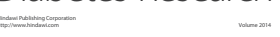

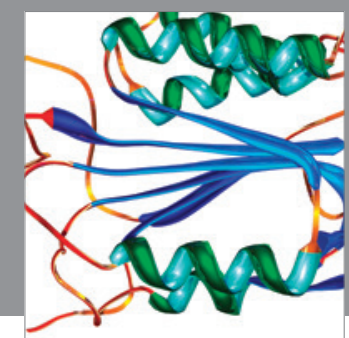

Disease Markers
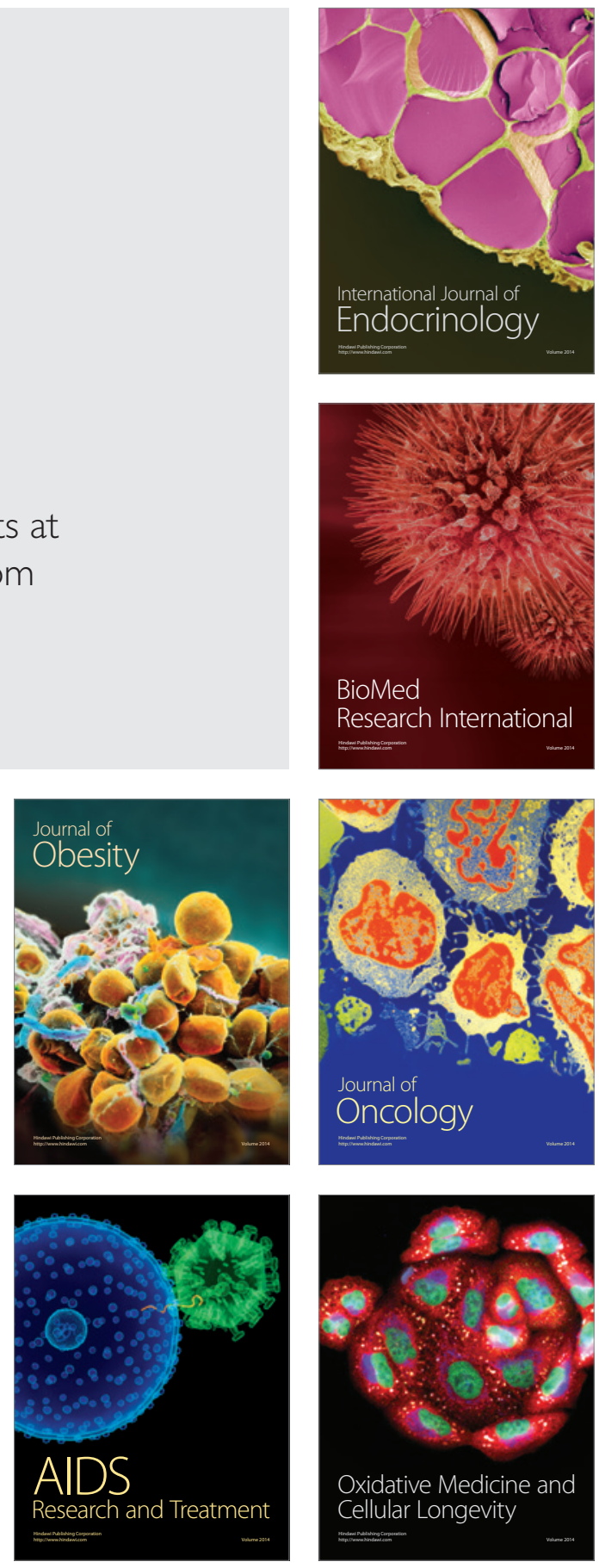